\title{
Further observations on the effect of balloon size on the short term and intermediate term results of balloon dilatation of the pulmonary valve
}

\author{
P SYAMASUNDAR RAO \\ From the Departments of Paediatrics, King Faisal Specialist Hospital and Research Centre, Riyadh, Saudi \\ Arabia and University of Wisconsin, School of Medicine, Madison, Wisconsin, USA
}

SUMMARY The relation between the size of the balloon used for dilatation of the pulmonary valve and the extent of relief of pulmonary stenosis both immediately after and at intermediate term follow up was studied. Sixty four balloon dilatation procedures in 56 patients were divided into group 1-12 in which the ratio of the diameter of the balloon to that of the pulmonary annulus was $\leqslant 1.0$ and group 2-52 in which the ratio was $>1 \cdot 0$. Both groups had similar mean (SD) pressure drops across the pulmonary valve before dilatation. Immediately after dilatation there was a significant reduction in the pulmonary valve gradient in both group $1(84.3(39 \cdot 2) v 43.6(26.8) \mathrm{mm}$ $\mathrm{Hg}$ ) and group $2(92.8(42 \cdot 1) v 22.4(13.6) \mathrm{mm} \mathrm{Hg})$. On intermediate term follow up (6-34 months), residual pulmonary valve gradients were significantly lower in group $2(20 \cdot 8(18.5) \mathrm{mm} \mathrm{Hg})$ than in group $1(75.0(49.4) \mathrm{mm} \mathrm{Hg})$, suggesting that restenosis was more common after dilatation with small balloons. These data suggest that although the immediate results with either small or large balloons are good, balloons that are larger than the pulmonary valve annulus produce more sustained relief of pulmonary stenosis. Further analysis within the group treated with larger balloons showed that the subgroup with a balloon/annulus ratio of $1.01-1.2$ had more recurrences of stenosis (need for repeat balloon dilatation and larger number of patients with residual pulmonary valve gradients $>30 \mathrm{~mm} \mathbf{H g}$ ) than subgroups with balloon/annulus ratios for diameters of $1 \cdot 21-1 \cdot 41,>1 \cdot 41$, and $>1.5$, in which there were no recurrences. Balloons that were $>1.5$ times the size of the pulmonary valve annulus had no additional advantage over the other subgroups, namely, $1 \cdot 21-1.4$ and $>1.41$.

These results and reports of damage to the right ventricular outflow tract by oversized $(>1.5)$ balloons indicate that balloons that give a balloon/annulus ratio of $1.2-1.5$ are the best for dilatation of the pulmonary valve.

In a previous study I reported on the relation between the size of the balloon used for balloon dilatation of the pulmonary valve and the degree of relief of pulmonary stenosis and I concluded that although the immediate results of dilatation are similar with both small and large balloons, balloons that are larger than the pulmonary valve annulus seem to produce more sustained relief of pulmonary stenosis on follow up. ${ }^{1}$ Therefore, I recommended balloons that were larger than the pulmonary valve annulus for balloon dilatation of the pulmonary

Requests for reprints to Dr P Syamasundar Rao, Division of Pediatric Cardiology, University of Wisconsin Hospital and Clinics, 600 Highland Avenue, Madison, $W$ isconsin 53792, USA.

Accepted for publication 2 August 1988 valve. Radtke et al reported similar relation between ballon size and the immediate results of dilatation. ${ }^{2}$ In view of the damage to the right ventricular outflow tract when balloons larger than 1.5 times the size of the pulmonary valve annulus were used, ${ }^{3}$ a balloon diameter to annulus diameter ratio of $1 \cdot 2-1 \cdot 4$ was recommended. ${ }^{12}$ This was an arbitrary recommendation without specific supporting data. I attempted to break down the group treated with large balloons into subgroups with various balloon/annulus ratios ${ }^{1}$ but I did not have sufficient cases in each subgroup to reach valid conclusions. In the present paper I present an evaluation of the effect of balloon size on balloon dilatation of the pulmonary valve in a much larger number of patients and examine what ratio of balloon size to pulmonary valve annulus is most 
apropriate for balloon dilatation in terms of the immediate and intermediate term follow up results.

\section{Patients and methods}

During a 50 month period ending in December 1987, 56 infants and children, aged seven days to 20 years (median six years) underwent 64 procedures for balloon dilatation of the pulmonary valve to relieve moderate to severe pulmonary valve stenosis. We obtained informed consent from the parents of each patient. The data obtained and the technique of percutaneous balloon dilatation of the pulmonary valve have been described in detail in earlier papers ${ }^{46}$ and they are similar to the technique used by others. ${ }^{78}$ Two balloons were used simultaneously for dilatation in twelve patients in whom the annular diameter was $>20 \mathrm{~mm}$. Initially, we did not use balloons that were larger than the pulmonary valve annulus; ${ }^{4}$ later we did. ${ }^{1}$ The size of the pulmonary valve annulus was measured from a frame of the lateral projection of the cineangiogram obtained before balloon dilatation and corrected for magnification. ${ }^{1}$ I used the balloon size listed by the manufacturer to calculate the balloon/annulus ratio. ${ }^{1}$ When two balloons were used simultaneously, the total balloon diameter was calculated according to the formula:

$$
\frac{D_{1}+D_{2}+\pi\left(\frac{D_{1}}{2}+\frac{D_{2}}{2}\right)}{\pi}
$$

where $D_{1}$ and $D_{2}$ are the diameters of the balloons used.

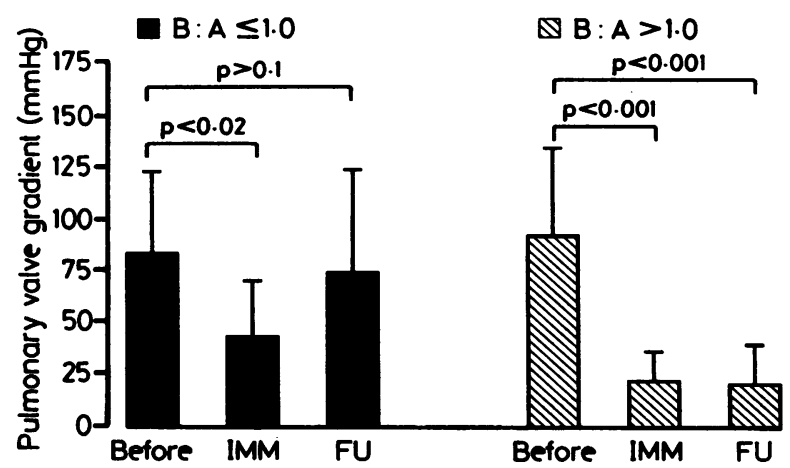

Fig 1 The peak pressure gradient across the pulmonary valve fell immediately (IMM) after balloon dilatation in both group 1 with small balloons $(p<0.02)$ and group 2 with large balloons $(p<0.001)$. On intermediate term follow up (FU), the gradient had risen towards predilatation values ( $p>0.1$ ) in group 1 patients (treated with balloons that were smaller than the pulmonary valve annulus) while in group 2 (balloons larger than the pulmonary valve annulus) the gradients remained low.
Balloon dilatation procedures were divided int $\theta$. two groups, based on the ratio between the balloor size and the size of the pulmonary valve annulus? group 1 with ratio of $\leqslant 1.0$ and group 2 with ratio of $>1 \cdot 0$. Group 2 was further subdivided into $2 \mathrm{a}$, ratio of 1.01 to $1.2 ; 2 b, 1.21$ to $1.4 ; 2 c,>1.41$; and $2 d_{\bar{\rho}}$ $>1.5$.

Follow up catheterisation was performed in 36 of 56 patients or 39 of the 64 dilatation procedures six to 34 months (mean 10.6 (SD) (6.7) months) after balloon dilatation. The cardiac index (mean (SD)d was obtained by a thermodilution technique in 33 patients and by the Fick method in the remaining patients. There was no difference $(p>0 \cdot 1)$ betweer the cardiac index before dilatation (3.18 (0.84) $1 / \mathrm{min} / \mathrm{m}^{2}$ ) and that measured immediately aftep dilatation $\left(3.16(0.68) 1 / \mathrm{min} / \mathrm{m}^{2}\right)$ or at follow uB (3.51 (0.8) $\left.1 / \mathrm{min} / \mathrm{m}^{2}\right)$.

I used a two tailed Student's $t$ test to compare dat $\vec{z}$ between groups and data obtained before and afte dilatation. The Bonferroni correction' was applie ${ }^{9}$ when multiple comparisons were made. Frequency distributions were compared by the $\chi^{2}$ test. The lever of statistical significance was set at $\mathbf{p}<0.05$.

\section{Results}

There was a total of 64 balloon dilatation procedure in 56 patients; intermediate term follow up was available in 36 patients. In group 1 , (12 dilatations) the mean (SD) balloon/annulus ratio was $0.89(0.08)$ (range, $0.76-1.0$ ); in group 2 (56 dilatations) the ratiog was $1.31(0.19)$ (range, 1.01-1.8). The peak systolic pressure gradients across the pulmonary valve before़े

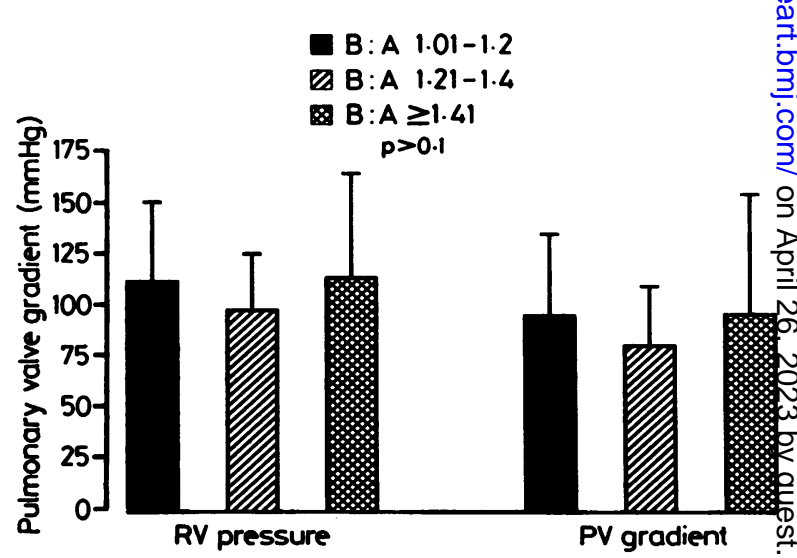

Fig 2 Right ventricular ( $R V$ ) peak systolic pressures and pulmonary valve (PV) gradients in all three group 2 subgroups were similar ( $p>0.1$ ) suggesting that in all the three groups there was a similar degree of pulmonary valve obstruction. 


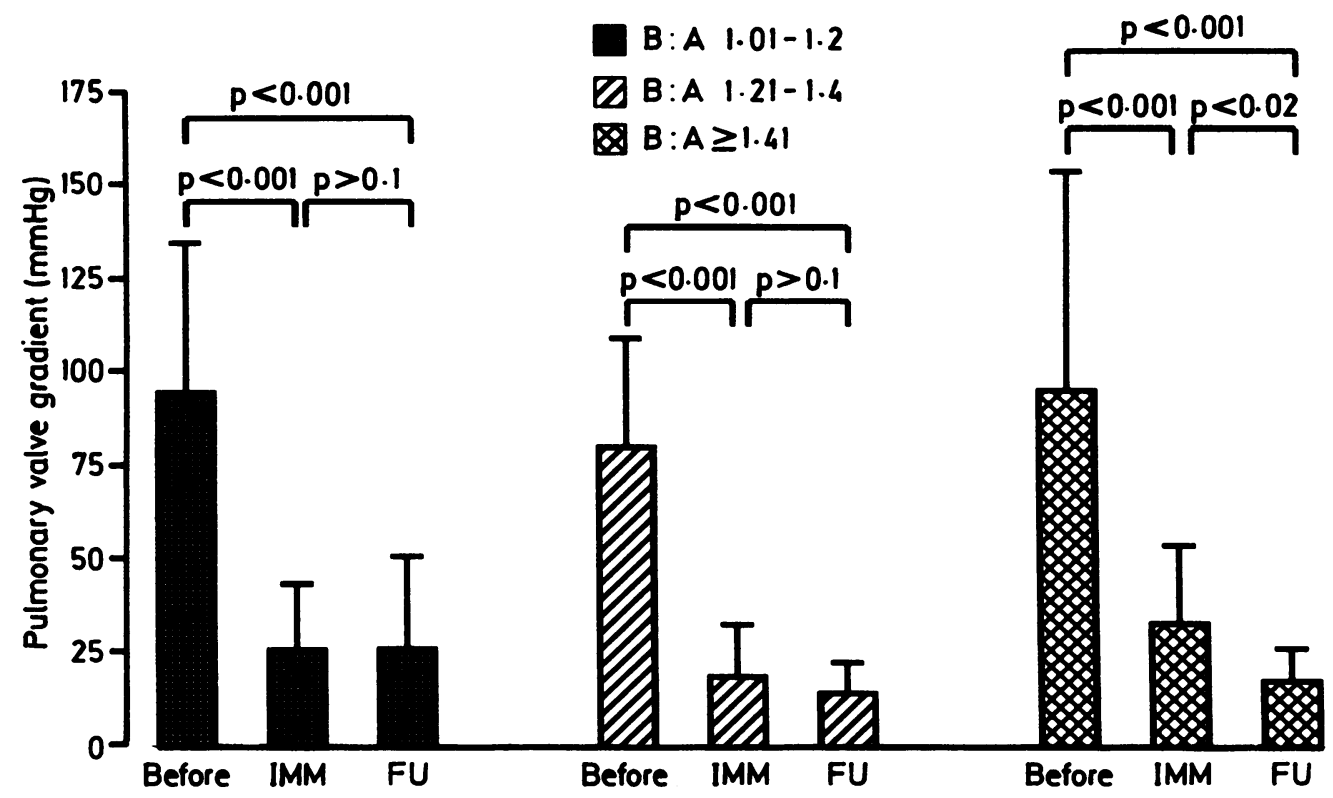

Fig 3 Peak systolic pressure gradients across the pulmonary valve fell $(p<0.001)$ immediately (IMM) after balloon dilatation in all three subgroups. On intermediate term follow up (FU), there was either no further change ( $p>1 \cdot 01$ ) (in subgroups with a balloon/annulus ratio of $1 \cdot 01-1 \cdot 2$ and $1 \cdot 21-1 \cdot 4$ ) or $a$ further fall $(p<0.02)$ (in the subgroup with balloon anulus ratio of $>1.41$ ).

dilatation were similar in both groups $(84.3$ (39.2) $v$ $29.8(42 \cdot 1) \mathrm{mm} \mathrm{Hg}, \mathrm{p}>0 \cdot 1)$.

Immediately after balloon dilatation the pulmonary valve gradient was significantly reduced in both group $1(84.3(39 \cdot 2) v(43.6(26.8) \mathrm{mm} \mathrm{Hg}, \mathrm{p}<0.02)$ and group $2(92.8(42.1) v 22.4(13.6) \mathrm{mm} \mathrm{Hg}$, $\mathrm{p}<0.001$ ) (fig 1). However, the residual pulmonary valve gradients in group 2 with large balloons $(22.4$ $(13.6) \mathrm{mm} \mathrm{Hg}$ ) were lower $(\mathrm{p}<0.01)$ than those in group 1 with small balloons $(43.6(26.8) \mathrm{mm} \mathrm{Hg})$.

On intermediate term follow up at 6-34 months, the pulmonary valve gradient $(75.0(49.4) \mathrm{mm} \mathrm{Hg})$ in group 1 had risen towards pre-dilatation values (84.3 (39.2)) and was not significantly different from such values ( $p>0 \cdot 1$ ) (fig 1$)$. In group 2 with large balloons the pulmonary valve gradient remained low $(20.8$ (18.5) $\mathrm{mm} \mathrm{Hg}$ ) and was not significantly different $(\mathrm{p}$ $>0 \cdot 1)$ from the gradient measured immediately after balloon dilatation. At follow up the right ventricular pressures $(97.7(50.6) v 45.5(17.2) \mathrm{mm} \mathrm{Hg}, \mathrm{p}<0.02)$ and pulmonary valve gradients $(75.0(49.4) v 20.8$ (8.5) $\mathrm{mm} \mathrm{Hg}, \mathrm{p}<0.01$ ) were higher in group 1 than those in group 2 at the follow up. Four of the group 1 patients and one group 2 patient needed repeat balloon dilatation at follow up $(p<0.005)$. There was Doppler echocardiographic evidence of mild pulmonary insufficiency in $\mathbf{3 3}$ of $\mathbf{3 6}$ group 2 patients and in three of seven group 1 patients $(p<0.005)$.
No other important complications were seen in either group.

Having confirmed that larger balloon/annulus ratios are associated with sustained relief of pulmonary valve obstruction on follow up, I further subdivided group 2 into group $2 a$ (balloon/annulus ratio, 1.01 to $1 \cdot 2,20$ patients), group $2 b$ (balloon/annulus ratio, 1.21 to $1.4,15$ patients), and group $2 \mathrm{c}$ (balloon/ annulus ratio $>1.41,17$ patients). The right ventricular peak systolic pressures and pulmonary valvar gradients were similar $(p>0.1)$ in those three subgroups (fig 2) although there were minor differences. Reduction of pulmonary valvar gradients immediately after and on intermediate term follow up was seen in all three groups (fig 3). In group 2c (with the largest balloon/annulus ratio $(>1.41)$ there was a further fall $(p<0.02)$ in the pulmonary valvar gradients at follow up $(18.4(8.1) \mathrm{mm} \mathrm{Hg})$ when compared to the value measured immediately after dilatation $(33.8(20 \cdot 1) \mathrm{mm} \mathrm{Hg})$. This may be related to the slightly higher residual pulmonary valvar gradients immediately after dilatation in this subgroup. When the number of patients with residual gradients $>30 \mathrm{~mm} \mathrm{Hg}$ or the number of patients requiring repeat balloon dilatation were compared (table), group 2a with balloon/annulus ratio of 1.011.20 had residual pulmonary valve obstruction while group $2 b$ (ratio 1.21-1.4) and group $2 c$ (ratio $>1 \cdot 41$ ) 
Table Frequency of repeat balloon and dilatation significant residual gradients in various subgroups

\begin{tabular}{|c|c|c|}
\hline & $\begin{array}{l}\text { Number of patients } \\
\text { needing repeat } \\
\text { dilatation }\end{array}$ & $\begin{array}{l}\text { Number of patients with } \\
\text { pulmonary valve } \\
\text { gradient }>30 \mathrm{~mm} \mathrm{Hg}\end{array}$ \\
\hline $\begin{array}{l}\text { Group } 1 \quad(n=7) \\
\text { Group } 2 \mathrm{a}(\mathbf{n}=13) \\
\text { Group } 2 \mathrm{~b}(\mathbf{n}=9) \\
\text { Group } 2 \mathrm{c}(\mathbf{n}=9)\end{array}$ & $\begin{array}{l}4 \\
1 \\
0 \\
0\end{array}$ & $\begin{array}{l}6 \\
2 \\
0 \\
0\end{array}$ \\
\hline
\end{tabular}

$\mathrm{n}=$ number of patients with intermediate term follow up catheterisation.

had none ( $<$ 0.005). Group 1 with balloon/annulus ratio $<1.0$ had the worst results (table).

Finally, the results of balloon dilatation of patients with balloon/annulus ratios $>1.5$ (group 2d, nine patients) were examined (because balloons as large as these are reported to damage the right ventricular outflow tract ${ }^{3}$ and were compared with group $2 b$ (balloon/annulus ratio, 1.21-1.4) to see whether there is any advantage in using these oversized balloons (fig 4). The right ventricular systolic pressures $(98.0(27 \cdot 1) v 99.0(36.9) \mathrm{mm} \mathrm{Hg}, \mathrm{p}>0 \cdot 1)$ and pulmonary valvar gradients $(80.7(28.6) v 82 \cdot 1(37 \cdot 4)$ $\mathrm{mm} \mathrm{Hg}, \mathrm{p}>0.1)$ were similar in both groups. Residual pulmonary valvar gradients immediately after dilatation $(19 \cdot 2(13.3) v 27.8(13.3), p>0 \cdot 1)$ and on follow up $(14.9(7.7) v 14.0(5.6), \mathrm{p}>0.1)$ were also similar. No patients needed repeat balloon dilatation in either group nor was there any patient with residual pulmonary valve gradient $>30 \mathrm{~mm}$ $\mathrm{Hg}$. There was no angiographic evidence of asymptomatic pulmonary arterial tears in either group.

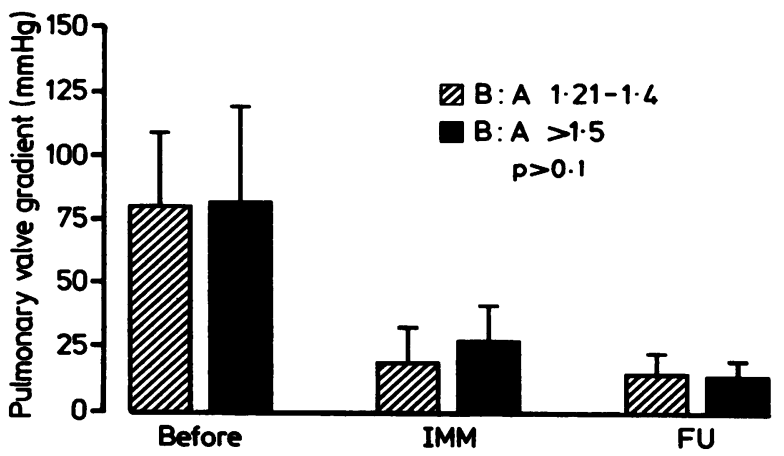

Fig 4 The peak systolic pressure gradient across the pulmonary valve before balloon dilatation and pulmonary valve gradients immediately (IMM) after dilatation and on intermediate term follow up (FU) were similar $(p>0.1)$ in both groups with balloon/annulus ratios of $1.21-1.4$ and $>$ 1.5 .

\section{Discussion}

It is generally agreed that it is better to use balloons? with diameters larger than pulmonary valve annulus: for balloon dilatation of pulmonary valve stenosis. ${ }^{1} \frac{\bar{g}}{\bar{c}}$. Balloon sizes 1.2-1.4 times the pulmonary annulus are recommended ${ }^{12}$ but there are no hard data to support such a recommendation. Experimentaf/ evidence indicates that the balloons $>1.5$ times size of the diameter of pulmonary valve annulus mayi damage the right ventricular outflow tract. ${ }^{3}$ Thew current study was designed to confirm that it is better? to use balloons that are larger than the pulmonary valve annulus to relieve stenosis of the pulmonaryo valve and to determine what size of balloon is needed for successful balloon dilatation of the pulmonaryo valve.

My results confirm that balloons larger than? pulmonary valve annulus are needed to produce $\vec{b}$ sustained relief of pulmonary valve obstruction $\Phi$ Breakdown of group 2 (larger balloon) into three subgroups showed that there is still a considerable degree of residual obstruction in the group with balloon/annulus ratio of 1.01-1.2. Intermediate terme results were similar in the subgroups with balloon $\%_{0}^{\circ}$ annulus ratios of $1 \cdot 21-1 \cdot 4$ and $>1 \cdot 41$. Balloons more than 1.5 times the size of the pulmonary valve annulus did not give better immediate or intermediate term results and may damage the righto ventricular outflow tract. ${ }^{3}$ The present data show that balloons that are less than 1.2 times the size of the pulmonary valve annulus are likely to be associatede with residual pulmonary valve obstruction on follow up and cannot be recommended. Balloons that are $>1.5$ times larger than pulmonary valve annulus do not have any additional advantage and therefore are not necessary. Thus balloons which are 1.2-1.5 times larger than the pulmonary valve annulus are the besto for relieving pulmonary valve stenosis.

I thank Dr M E Fawzy, Dr M K Mardini, Dr L Solymar, and Dr M K Thapar for their contribution? to this study. I also thank P Carey for the advice on statistical analysis.

\section{References}

1 Rao PS. Influence of balloon size on the short-term and long-term results of balloon pulmonary valvulo-? plasty. Texas Heart Inst $J$ 1987;14:57-61.

2 Radtke W, Keane JF, Fellows KE, Lang P, Lock JE. Percutaneous balloon valvotomy of congenital pulmonary stenosis using over-sized balloons. J Am Coll Cardiol 1986;8:909-15. 
3 Ring JC, Kulik TJ, Burke BA, Lock JE. Morphologic changes induced by dilatation of the pulmonary valve annulus with over-large balloons in normal newborn lambs. Am J Cardiol 1984;55:210-4.

4 Rao PS, Mardini MK. Pulmonary valvotomy without thoracotomy: the experience with percutaneous balloon pulmonary valvuloplasty. Ann Saudi Med 1985;5:149-55.

5 Rao PS. Transcatheter treatment of pulmonary stenosis and coarctation of the aorta: experience with percutaneous balloon dilatation. Br Heart J 1986;56: 250-8.
6 Rao PS, Fawzy ME, Solymar L, Mardini MK. Longterm results of balloon pulmonary valvuloplasty of valvar pulmonic stenosis. Am Heart J 1988;115: $1291-6$.

7 Kan JS, White RI, Mitchell SE, Anderson JH, Gardner TJ. Percutaneous transluminal balloon valvuloplasty for pulmonary valve stenosis. Circulation 1984;69: 554-60.

8 Lababidi Z, Wu JR. Percutaneous balloon pulmonary valvuloplasty. Am J Cardiol 1983;52:560-2.

9 Glantz SA. Primer of biostatistics. New York: McGrawHill, 1981. 